\title{
Sympathovagal balance changes in sleep breathing disorders
}

\author{
Vincenzo Patruno1 \\ Orietta Coletti 1 \\ Eleonora Tobaldini2 \\ Nicola Montano2 \\ ${ }^{1}$ Division of Pulmonary Rehabilitation, IMFR, Udine, \\ Italy \\ ${ }^{2}$ Department of Clinical Sciences, Internal Medicine \\ II, University of Milan, Milan, Italy
}

Address for correspondence:

Vincenzo Patruno, MD

Division of Pulmonary Rehabilitation, I.M.F.R.

Udine, Italy

E-mail: vincenzo.patruno@gmail.com

\section{Summary}

The autonomic nervous system (ANS) plays a leading role in controlling visceral functions and it is well known that the increase of sympathetic activity underlies most of cardiovascular diseases such as hypertension, heart failure, myocardial infarction and arrhythmias. On the other hand parasympathetic activity acts as protective factor against the above mentioned conditions.

Sleep breathing disorders (SBD) are commonly divided in three syndromes: obstructive sleep apnoea syndrome, central sleep apnoea syndrome and Cheyne-Stokes breathing syndrome, the latter two both characterized by cyclic non-obstructive breathing patterns. Cheyne-Stokes Respiration is a form of periodic breathing characterized by a crescendo-decrescendo pattern of ventilation with (CSR-CSA) or without (CSR) central apnoea.

Obstructive sleep apnea (OSA) is significantly associated with increased cardiovascular morbidity and mortality.

OSA exerts strong modulatory effects on the autonomic nervous system through a number of mechanisms including central respiratory-cardiac coupling in the brain stem, chemo-reflex stimulation, baro-reflexes, and reflexes relating to lung inflation. EEG arousals, often related to apnea termination, also represent the final way of autonomic activation.

CSR is common among patients with congestive heart failure, being present in $30-40 \%$ of the two largest reported.

If CSR "per se" promotes an increase of sympathetic outflow during sleep is not really known.

Several lines of argument would support the hypothesis that CSR may be a compensatory mechanism for severe HF.

KEY WORDS: autonomic nervous system, obstructive sleep apnea, Cheyne-Stokes Respiration.

\section{Introduction}

Obstructive sleep apnoea (OSA) is significantly associated with increased cardiovascular morbidity and mortality $(1,2)$

However, one of the most quoted potential links between OSA and cardiovascular diseases is thought to be the increased sympathetic drive (3).

CSA-CSR is common among patients with congestive heart failure.

Increased sympathetic drive is related to an increased mortality in patients with congestive heart failure and OSA.

mainly focus on autonomic neural mechanisms observed during obstructive sleep apnea and during the crescendo-decrescendo ventilatory pattern of Cheyne-Stokes Respiration also in light of new hypothesis about the role of CSR in HF.

\section{Autonomic Nervous System}

The autonomic nervous system (ANS) plays a leading role in controlling visceral functions and it is well known that the increase of sympathetic activity underlies most of cardiovascular diseases such as hypertension, heart failure, myocardial infarction and arrhythmias. On the other hand parasympathetic activity acts as protective factor against the above mentioned conditions (4)

Some studies have recently highlighted the ANS involvement in the inflammatory response and in altering the endothelial function. Therefore underlying the key-role of ANS which acts as interface between central nervous system and body (5).

On this basis, researchers are highly interested in as-
The spectral analysis of heart rate variability is a noninvasive technique for assessing the balance between sympathetic and parasympathetic cardiovascular activity. 
sessing how the sympatho-vagal balance varies among different conditions.

Nowadays, the spectral analysis of heart rate variability is the most used technique for assessing the balance between sympathetic and parasympathetic cardiovascular activity and, in addition, is a non-invasive procedure. It quantifies low-frequency (LF; sympathetic modulation marker) and high-frequency (HF; vagal modulation marker and synchronous with respiration) oscillation bands over short-term or long-term recordings.

Many studies prove how the majority of cardiovascular diseases is associated with increased LF bands and reduced total heart rate variability and how these parameters can be considered independent risk predictors for cardiovascular disorders (6).

A non-invasive approach based on the spectral analysis of heart rate variability (HRV), able to provide semi-quantitative information on the cardiovascular balance between sympathetic and parasympathetic modulations, has allowed to provide important information on autonomic control mechanisms both in pathophysiological (7) and clinical studies (8) mostly in sleep studies.

The oscillatory pattern, which characterizes the spectral profile of HRV, consists of two major components, at low (LF, 0.04-0.15 Hz) and high (HF, synchronous with respiratory rate) frequency, respectively related to sympathetic and respiratory vagal modulation, when expressed in normalized units (nu). LF/HF ratio can be used as a synthetic measure of the sympathovagal balance.

In general spectral methodologies should be applied only to relatively stationary conditions (9). When transitory (i.e. non stationary) states have to be analyzed, specific time-frequency domain algorithms are required (10-12).

\section{Sleep and ANS}

Sleep is characterized by two distinct neurophysiological states: non-rapid eye movements (NREM) and rapid eye movements (REM) (13). Recently (14) NREM sleep was classified into three different stages (1,2 and SWS).

During non-REM sleep stages, the ANS undergoes cyclic alterations characterized by the progressive reduction of sympathetic activity and, consequently, of heart rate and blood pressure (15).

On the other hand, during REM sleep stage the increased cortical activity is associated with rapid boosts in blood pressure, heart rate and sympathetic activity, the latter even reaching thought-like mental activity levels (15).

Physiological changes in the nervous control of circulation occurring during sleep have been recently confirmed thanks to the spectral analysis of heart rate variability which identified alterations of sympatheticvagal balance even in sleep microstructure (CAP and non-CAP cycles) (16). Sleep can be interrupted by brief arousals, either spontaneously or in response to

sleep-disordered breathing or other stimuli. Arousals are associated with abrupt increases in the respiratory drive; indeed, the augmented ventilation accompanying arousals exceeds that expected for the prevailing $\mathrm{PaCO}_{2}$.

Abrupt increases in BP and HR, because of sudden increases in sympathetic nervous activity and withdrawal of cardiac vagal activity, also exceed waking levels (17) indicating that arousal is a transient but distinct state of heightened respiratory and cardiovascular activity $(18,19)$.

\section{Sleep breathing disorders and ANS}

Sleep breathing disorders (SBD) are commonly divided into three syndromes (14): obstructive sleep apnoea syndrome, central sleep apnoea-hypopnoea syndrome and Cheyne-Stokes breathing syndrome, the latter two both characterized by cyclic non-obstructive breathing patterns. CSR is a form of periodic breathing in which apneas/hypopneas alternate with ventilatory periods having a crescendo-decrescendo pattern of tidal volume. OSA has an estimated prevalence of $9-24 \%$ in middle-aged population $(20,21)$ and has emerged as an important cardiovascular risk factor. In recent years, OSA has been linked to a higher relative risk for cardiovascular diseases, such as arterial hypertension, congestive heart failure, arrhythmias, and sudden cardiac death $(22,23)$.

One of the most relevant pathophysiological factors detected in OSA patients is an heightened sympathetic activity. During the obstructive episodes, important fluctuations in heart rate, blood pressure and muscle

OSA has been linked to a higher relative risk for cardiovascular diseases, such as arterial hypertension, congestive hearth failure, arrhythmias, and sudden cardiac death. sympathetic nerve activity were first described by Somers et al. (3). A cascade of consecutive events may explain the autonomic changes observed during nighttime. First, the lack of the normal sympathoinhibition induced by lung inflation reflexes and the exaggerated central respiratory drive due to an inefficient respiratory effort leave an unbalanced sympathetic drive. Chronic intermittent chemoreceptor activation induced by hypoxia and hypercapnia are associated with a coactivation of sym-

pathetic and parasympathetic drive (24) inducing brady-

One of the most remarkable characteristics of OSA is the presence of an heightened sympathetic activity also during wakefulness, as demonstrated by MSNA recordings and spectral analysis of HRV. cardic-tachycardic heart rate responses, peripheral vasoconstriction and progressive increase in peripheral sympathetic drive. The forced inspiration with closed glottis (Muller maneuver), drastically modifying intrathoracic pressures, induces relevant changes in heart chamber size, re- 


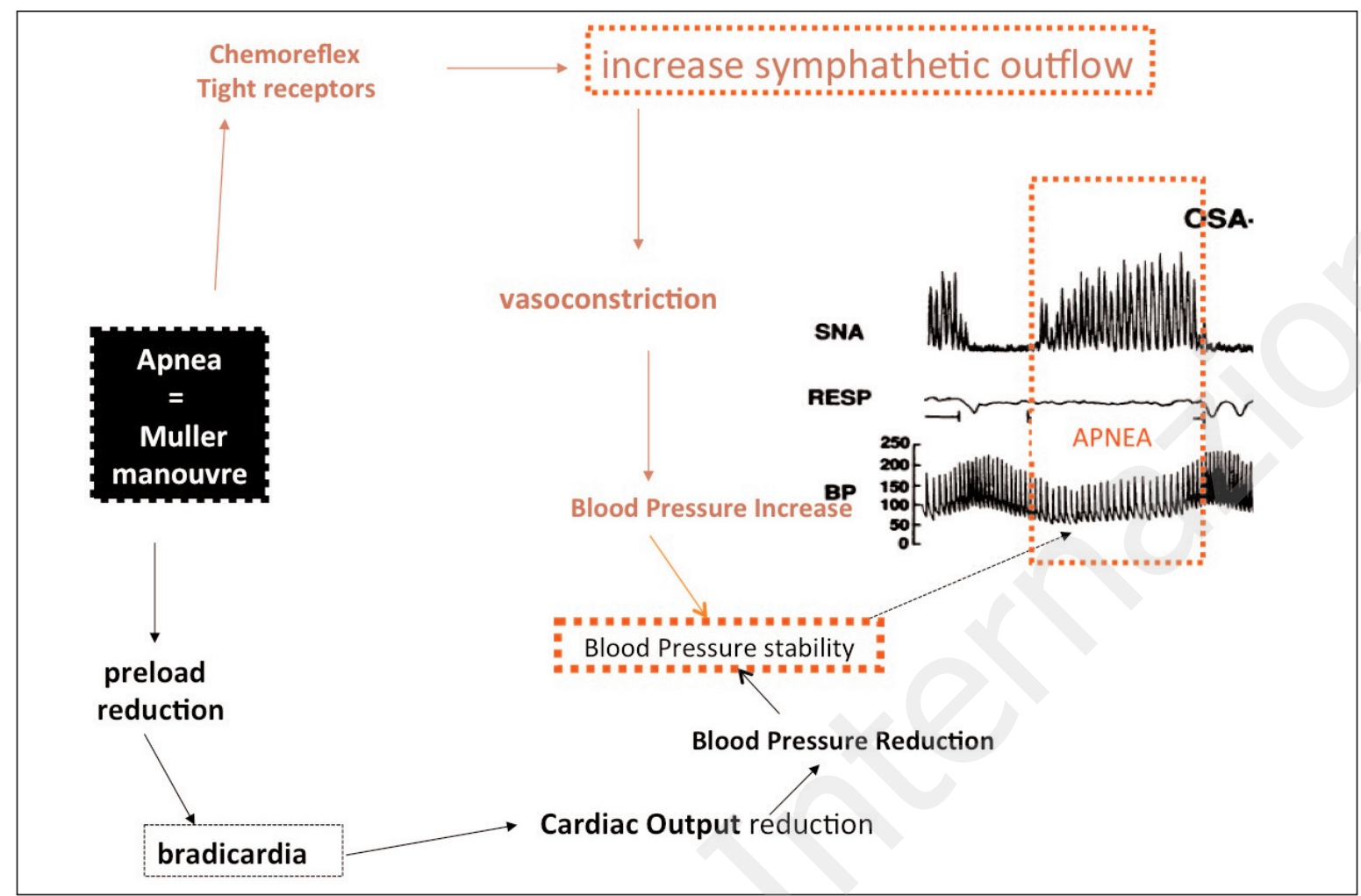

Figure 1 - Increase of symphathetic outflow, bradicardia and stability of blood pressure during the obstructive apnea. (See text for details).

duction in blood pressure and an initial inhibition of sympathetic drive, likely to and due to a mechanical stretching effect on cardiac vagal afferent fibers (Figure 1). Immediately after the cessation of the obstructive event, upper airways patency is associated with an increase in cardiac output which, superimposed to the preceding sympathetic vasoconstriction, determines a considerable increase in blood pressure, a consequent activation of baroreceptor and lung pulmonary inflation reflexes thus inducing a transient shutdown of sympathetic drive (25) (Figure 2). Arousals appearing at the end of apneas increase the nighttime sympathetic-excitation even more.

This cycle may repeat itself hundreds of time during sleep, thus inducing an overall effect of nighttime sympathetic-excitation and surges of blood pressure, responsible for the "non-dipping" profile of blood pressure.

However, one of the most remarkable characteristics of OSA is the presence of an heightened sympathetic activity also during wakefulness, as demonstrated by MSNA recordings $(3,26)$ and spectral analysis of HRV (27). The mechanisms implicated in this phenomenon are still unclear. Firstly, it has been hypothesized that the effect of sympathetic excitation induced by hypoxia might persist for a long time, also during normo-oxygenation conditions $(28,29)$. Secondly, a potentiation of peripheral chemo-reflex responses has been detected in OSA subjects, possibly contributing to maintain a tonic sympathetic excitation during wakefulness
(27, 30). Lastly, a depressed baro-reflex sensitivity (BRS) was reported, although most studies assessed baroreceptor responses only during sleep (31-34) while those reporting wakefulness data concluded that BRS was unchanged $(35,36)$ (Figure 3).

Available evidence (37) indicates that chronic intermittent hypoxia $(\mathrm{CHI})$ exerts two major effects on the chemoreceptor reflex: (a) augmentation of the carotid body and sympathetic effector responses to acute hypoxia; and (b) induction of long-lasting activation of both the sensor and the effector that persists several hours after the cease of $\mathrm{CIH}$. Moreover, other nonneural factors that have recently been proposed to participate as intermediate mechanisms in linking OSA and cardiovascular disorders, such as systemic inflammation and endothelial dysfunction (38) might contribute to maintaining an elevated sympathetic activation during wakefulness. However, sympathetic activation per se might sustain an increased oxidative stress, an altered endothelial dysfunction and a chronic activation of the inflammatory cascade. Thus a "vicious circle" between systemic inflammation and oversympathetic activity is likely to be sustained.

Central sleep apnea (CSA) differs from OSA in that central apneas are associated with absent respiratory effort. Cheyne-Stokes Respiration (CSR) is a form of CSA in which an apneic phase alternates with ventilatory periods (hyperpneic phase) having a crescendodecrescendo pattern of tidal volume. Although less common than OSA overall, CSR is very common in 


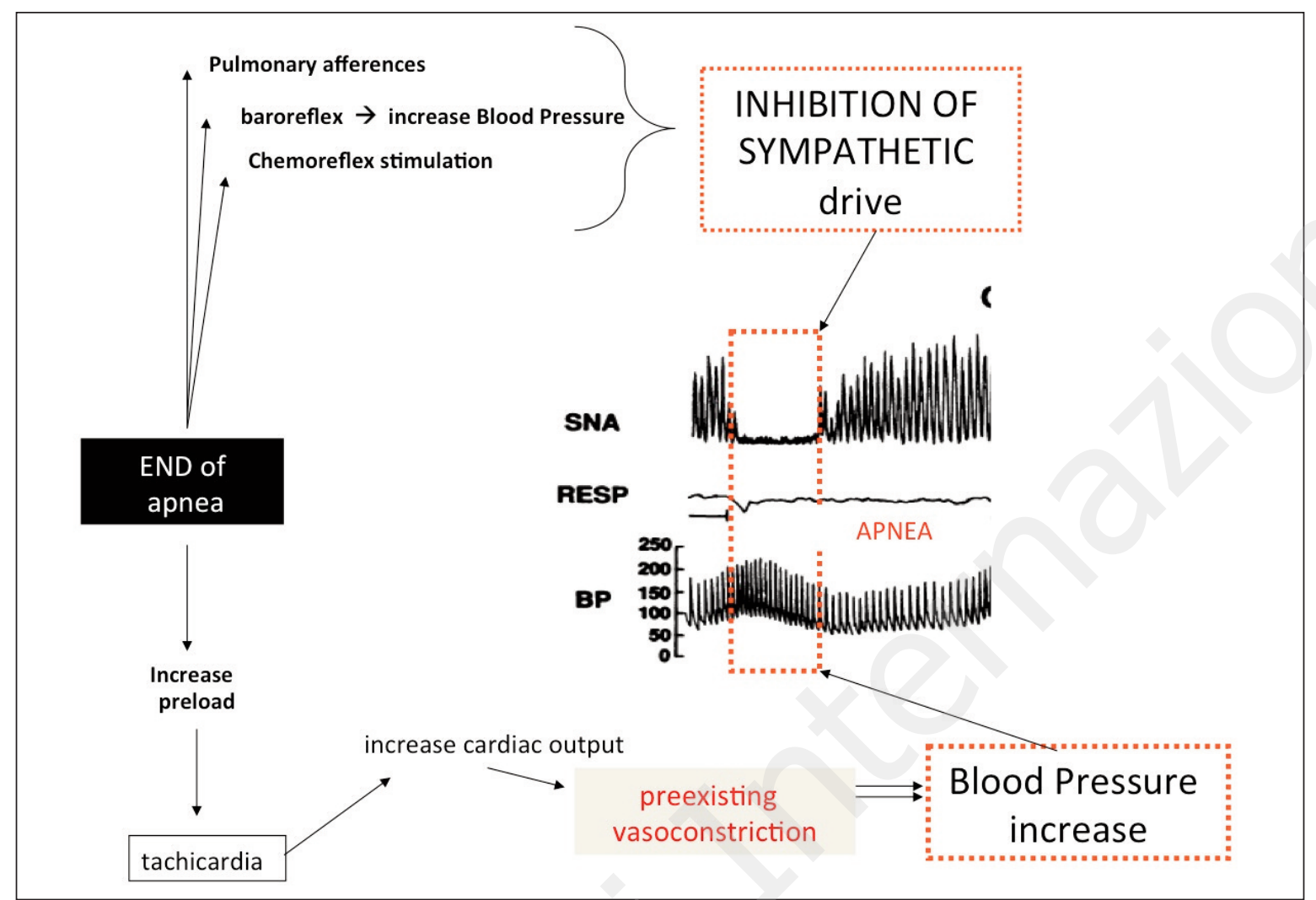

Figure 2 - Increase of blood pressure, tachicardia and inhibition of sympathetic drive at the apnea-termination. (See text for details).

subjects exposed to high altitude (39) and among patients with CHF (24). It is not yet known whether CSR is an epiphenomenon in the setting of heart failure or whether it may itself lead to increased risk or progression of heart failure (40).

CSR is associated with heart rate and blood pressure oscillations, in phase with respiration (40). However the precise mechanism linking CSR-CSA with BP and $\mathrm{HR}$ oscillations remains to be determined.

$\mathrm{HR}$ and BP oscillations associated with CSR- CSA are more tightly linked to oscillations in ventilation than to fluctuations in SaO2. Data from Leung et al. (41) demonstrate that periodic oscillations in BP and HR are not dependent on episodic hypoxia. When intermittent hypoxia was eliminated by $\mathrm{O} 2$ inhalation, oscillations in HR and BP remained associated with oscillations in ventilation. These oscillations are coupled to similar increases in sympathetic activity and are not due to chemo- or baroreceptor sympathetic activation. Also arousals have been shown to have little effect on BP during CSR-CSA (18) (Figure 4).

A more likely explanation for the simultaneous increases in HR and BP is a parallel increase in sympathetic drive to the heart and peripheral vasculature (42). Since vagal tone is markedly impaired in patients with heart failure (43), this sympathetically mediated rise in BP cannot be buffered by baroreflex-mediated parasympathetic withdrawal.

Recently Ueno et al. (44) reported that heart failure patients with central sleep apnea have an impaired HRV and BRS, with blunted 24-hours changes, in comparison with heart failure patients without sleep apnea.

On the other hand, deep breaths of periodic breathing and lung inflation promote vagal and reduce sympathetic activity in normal subjects (45) and large tidal breaths (similar to CSA-CSR) were shown to attenuate MSNA in a group of HF patients during wakefulness (46).

During sleep, periods of CSA-CSR were associated with a small rise in overall MSNA; however, attenuation of the MSNA occurred during the hyperventilation phase (47) consistent with the hypothesis that large swings in tidal volume attenuate sympathetic activity. Finally, CSA-CSR has been observed to be associated with greater sympathetic activity compared with control groups without sleep apneas (48). However, when controlled for the severity of HF (i.e., with pulmonary artery pressure) the additional effect of apnea type (either CSA-CSR or OSA) on sympathetic activity seems to be negligible $(46,49)$.

\section{Conclusions}

Most of patients with recurrent obstructive apnoea exhibit autonomic abnormalities, including persistent elevations in sympathetic nerve activity, which can be explained with respiratory mechanisms related to apnoea duration or with the cortical mechanisms related 


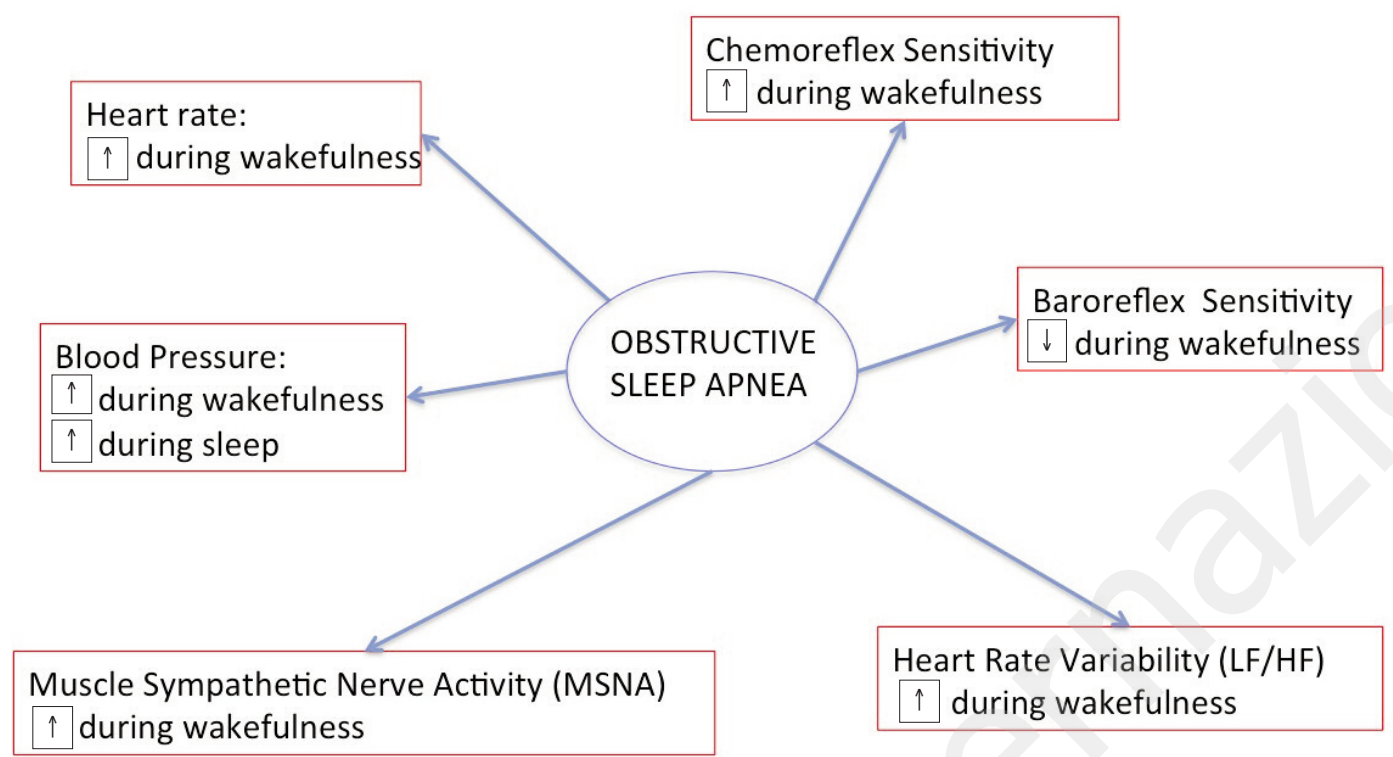

Figure 3 - Schematically representation of relationship between OSA and ANS during sleep and wakefulness. (See text for details).

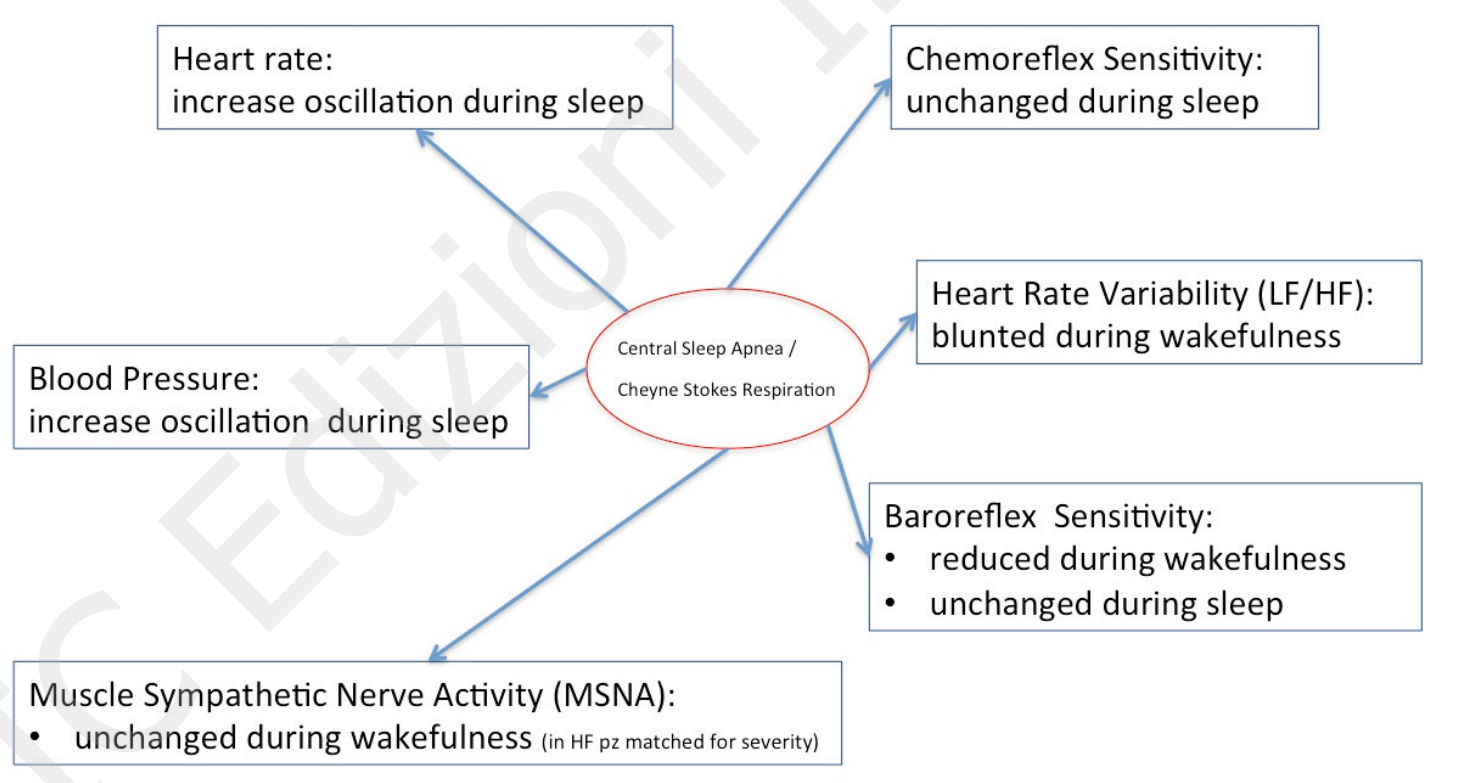

Figure 4 - Schematically representation of relationship between CSA-CSR and ANS during sleep and wakefulness. (See text for details).

to apnoea termination.

Obstructive sleep apneas exert strong modulatory effects on the autonomic nervous system through a number of mechanisms including central respiratorycardiac coupling in the brain stem, chemo-reflex stimulation, baro-reflexes, and reflexes related to lung inflation. EEG arousals, often related to apnea termination, also represent the final way of autonomic activation.
Central apneas are mostly associated to heart failure and expressed in the context of CSR. CSA-CSR increases oscillation of $\mathrm{HR}$ and BP during sleep but have no effect on chemo and baro-reflex sensitivity during sleep and have no
Several lines of argument would support the hypothesis that CSA-CSR may be a compensatory mechanism for severe heart failure. 
effect on MSNA activity during wakefulness in HF patient when well matched for HF severity.

If CSR-CSA "per se" promotes an increase of sympathetic outflow during sleep is not really known. Several lines of argument would support the hypothesis that CSA-CSR may be a compensatory mechanism for severe HF.

\section{Disclosure}

All Authors have no financial or other potential conflicts of interest to disclose.

\section{References}

1. Nieto FJ, Young TB, Lind BK, Shahar E, Samet JM, Redline S, et al. Association of sleep- disordered breathing, sleep apnea, and hypertension in a large community-based study. JAMA. 2000;283:1829-36.

2. Punjabi NM, Caffo BS, Goodwin JL, Gottlieb DJ, Newman AB, O'Connor GT, et al. Sleep-disordered breathing and mortality: a prospective cohort study. PLoS Med. 2009;6:e1000132.

3. Somers VK, Dyken ME, Clary MP, Abboud FM. Sympathetic neural mechanism in obstructive sleep apnea. J Clin Invest. 1995;96:1897-904.

4. Malliani A, Montano N. Emerging Excitatory Role of Cardiovascular Sympathetic Afferents in Pathophysiological Conditions. Hypertension. 2002;39:63-68.

5. Tracey KJ. The inflammatory reflex. Nature. 2002; 420:853-862.

6. Montano N, Cogliati C, Dias da Silva V, Gnecchi Ruscone T, Malliani A. Sympathetic rhythms and cardiovascular oscillations. Auton Neurosci. 2001;90: 29-34.

7. Wallin G. Intraneural recording and autonomic function in man. In: Bannister, R._Ed., Autonomic Failure. Oxford University, London, UK, 1983, pp. 36-51

8. Montano N, Porta A, Cogliati C, Costantino G, Tobaldini E, Casali KR, lellamo F. Heart rate variability explored in the frequency domain: a tool to investigate the link between heart and behavior. Neurosci Biobehav Rev. 2009;33(2):71-80.

9. Task Force of the European Society of Cardiology the North American Society of Pacing Electrophysiolog. Heart Rate Variability. Standards of Measurement, Physiological Interpretation, and Clinical Use. Circulation. 1996;93:1043-1065

10. Jasson S, Médigue $C$, Maison-Blanche $P$, Montano $\mathrm{N}$, Meyer L, Vermeiren C, Mansier P, Coumel P, Malliani A, Swynghedauw B. Instant power spectrum analysis of heart rate variability during orthostatic tilt using a time-/frequency-domain method. Circulation. 1997;96(10):3521-6.

11. Guggisberg AG, Hess CW, Mathis J. The significance of the sympathetic nervous system in the pathophysiology of periodic leg movements in sleep. Sleep. 2007;30:755-66.

12. Mendez MO, Bianchi AM, Montano N, Patruno V, Gil
E, Mantaras C, Aiolfi S, Cerutti S. On arousal from sleep: time-frequency analysis. Med Biol Eng Comput. 2008;46(4):341-51.

13. Rechtschaffen A, Kales A. A manual of standardised terminology, techniques and scoring for sleep stages of human subjects. Brain information Service/Brain Research Institute. University of California at ULCA, Los Angeles, 1968.

14. Berry RB, Budhiraja R, Gottlieb DJ, Gozal D, Iber C Kapur VK, Marcus CL, Mehra R, Parthasarathy S, Quan SF, Redline S, Strohl KP, Davidson Ward SL, Tangredi MM; American Academy of Sleep Medicine. Rules for scoring respiratory events in sleep: update of the 2007 AASM Manual for the Scoring of Sleep and Associated Events. Deliberations of the Sleep Apnoea Definitions Task Force of the American Academy of Sleep Medicine. J Clin Sleep Med. 2012;8(5):597-619.

15. Somers VK, Dyken ME, Mark AL, Abboud FM. Sympathetic nerve activity during sleep in normal humans. N Engl J Med. 1993;328:303-307.

16. Iellamo F, Placidi F, Marciani MG, Romigi A, Tombini M, Aquilani S, Massaro M, Galante A, Legramante JM. Baroreflex Buffering of Sympathetic Activation During Sleep Evidence From Autonomic Assessment of Sleep Macroarchitecture and Microarchitecture. Hypertension. 2004;43:814-819.

17. Horner RL, Brooks D, Kozar LF, et al. Immediate effects of arousal from sleep on cardiac autonomic outflow in the absence of breathing in dogs. J Appl Physiol. 1995;79:151-162.

18. Trinder J, Merson R, Rosenberg JI, et al. Pathophysiological interactions of ventilation, arousals, and blood pressure oscillations during CheyneStokes respiration in patients with heart failure. Am J Respir Crit Care Med. 2000;162:808-813.

19. Horner RL, Rivera MP, Kozar LF, et al. The ventilatory response to arousal from sleep is not fully explained by differences in $\mathrm{CO} 2$ levels between sleep and wakefulness. J Physiol. 2001;534:881-890.

20. Usmani ZA, Chai-Coetzer CL, Antic NA, McEvoy RD.Obstructive sleep apnoea in adults. Postgrad Med J. 2013;89:148-56.

21. Strohl KP, Brown DB, Collop N, George C, Grunstein R, Han F, Kline L, Malhotra A, Pack A, Phillips B, Rodenstein D, Schwab R, Weaver T, Wilson K; ATS Ad Hoc Committee on Sleep Apnoea, Sleepiness, and Driving Risk in Noncommercial Drivers.An official American Thoracic Society Clinical Practice Guideline: sleep apnoea, sleepiness, and driving risk in noncommercial drivers. An update of a 1994 Statement. Am J Respir Crit Care Med. 2013;187(11): 1259-66.

22. Somers VK, White DP, Amin R, Abraham WT, Costa F, Culebras A, Daniels S, Floras JS, Hunt CE, Olson LJ, Pickering TG, Russell R, Woo M, Young T; American Heart Association Council for High Blood Pressure Research Professional Education Committee, Council on Clinical Cardiology; American Heart Association Stroke Council; American Heart Association Council on Cardiovascular Nursing; American Col- 
lege of Cardiology Foundation.Sleep apnoea and cardiovascular disease: an American Heart Association/american College Of Cardiology Foundation Scientific Statement from the American Heart Association Council for High Blood Pressure Research Professional Education Committee, Council on Clinical Cardiology, Stroke Council, and Council On Cardiovascular Nursing. In collaboration with the National Heart, Lung, and Blood Institute National Center on Sleep Disorders Research (National Institutes of Health). Circulation. 2008;118(10):1080-111.

23. Dong JY, Zhang YH, Qin LQ.Obstructive sleep apnoea and cardiovascular risk: meta-analysis of prospective cohort studies. Atherosclerosis. 2013; 229(2):489-95.

24. Paton JF, St-John WM. Long-term intracellular recordings of respiratory neuronal activities in situ during eupnea, gasping and blockade of synaptic transmission. J Neurosci Methods. 2005;147(2):13845.

25. Dempsey JA, Veasey SC, Morgan BJ, O’Donnell CP.Pathophysiology of sleep apnoea. Physiol Rev. 2010;90(1):47-112.

26. Carlson JT, Hedner J, Elam M, Ejnell H, Sellgren J, Wallin BG. Augmented resting sympathetic activity in awake patients with obstructive sleep apnea. Chest. 1993;103:1763-1768.

27. Narkiewicz, K, Montano N, Cogliati C, van de Borne PJH, Dyken ME, Somers VK. Altered cardiovascular variability in obstructive sleep apnea. Circulation. 1998;98:1071-1077.

28. Morgan BJ, Crabtree DC, Palta M, Skatrud JB. Combined hypoxia and hypercapnia evokes long-lasting sympathetic activation in humans. J Appl Physiol. 1995;79(1):205-13.

29. Tamisier R, Pépin JL, Rémy J, Baguet JP, Taylor JA, Weiss JW, Lévy P. 14 nights of intermittent hypoxia elevate daytime blood pressure and sympathetic activity in healthy humans. Eur Respir J. 2011;37 (1):119-28.

30. Narkiewicz K, van de Borne PJH, Pesek CA, Dyken ME, Montano N and Somers VK Selective Potentiation of Peripheral Chemoreflex Sensitivity in Obstructive Sleep Apnoea. Circulation. 1999;99:11831189.

31. Parati G, Di Rienzo M, Bonsignore MR, Insalaco G, Marrone O, Castiglioni P, Bonsignore G, Mancia G. Autonomic cardiac regulation in obstructive sleep apnoea syndrome: evidence from spontaneous baroreflex analysis during sleep. J Hypertens. 1997;15:1621-6.

32. Bonsignore MR, Parati G, Insalaco G, Castiglioni P, Marrone O, Romano S, Salvaggio A, Mancia G, Bonsignore G, Di Rienzo M. Baroreflex control of heart rate during sleep in severe obstructive sleep apnoea: effects of acute CPAP. Eur Respir J. 2006 Jan;27(1):128-35.

33. McNicholas WT, Bonsigore MR. Sleep apnoea as an independent risk factor for cardiovascular disease: current evidence, basic mechanisms and research priorities. Eur Respir J. 2007;29(1):156-78.
34. McConnell K, Somers VK, Kimball T, Daniels S, VanDyke R, Fenchel M, Cohen A, Willging P, Shamsuzzaman A, Amin R. Baroreflex gain in children with obstructive sleep apnoea. Am J Respir Crit Care Med. 2009;180(1):42-8.

35. Narkiewicz K, Pesek CA, Kato M, Phillips BG, Davison DE, Somers VK. Baroreflex control of sympathetic nerve activity and heart rate in obstructive sleep apnoea. Hypertension. 1998;32(6):1039-43.

36. Ziegler MG, Nelesen RA, Mills PJ, Ancoli-Israel S, Clausen JL, Watkins L, Dimsdale JE. The effect of hypoxia on baroreflexes and pressor sensitivity in sleep apnoea and hypertension. Sleep. 1995;18 (10):859-65.

37. Nanduri R. Prabhakar, Thomas E. Dick, Jayasri Nanduri, Ganesh K. Kumar Systemic, cellular and molecular analysis of chemoreflex-mediated sympathoexcitation by chronic intermittent hypoxia. Exp Physiol. 2007;92(1):39-44.

38. Gozal D, Kheirandish-Gozal L. Cardiovascular morbidity in obstructive sleep apnoea: oxidative stress, inflammation, and much more. Am J Respir Crit Care Med. 2008;177(4):369-75.

39. Salvaggio A, Insalaco G, Marrone O, Romano S, Braghiroli A, Lanfranchi P, Patruno V. Effects of highaltitude periodic breathing on sleep and arterial oxyhaemoglobin saturation. Eur Respir J. 1998;12 :408413.

40. Naughton MT. Cheyne-Stokes respiration: friend or foe? Thorax. 2012;67(4):357-60.

41. Leung RST, Floras JS, Lorenzi-Filho G, Rankin F, Picton P, Bradley DT. Influence of Cheyne-Stokes Respiration on Cardiovascular Oscillations in Heart Failure. Am J Respir Crit Care Med. 2003:167:153439.

42. Floras JS. Clinical aspects of sympathetic activation and parasympathetic withdrawal in heart failure. J Am Coll Cardiol. 1993;22:72-84.

43. Nolan J, Flapan AD, Capewell S, MacDonald TM, Neilson JM, Ewing DJ. Decreased cardiac parasympathetic activity in chronic heart failure and its relation to left ventricular function. Br Heart J. 1992; 67:482-485.

44. Ueno LM, Drager LF, Rodrigues AC, Rondon MU, Mathias W Jr, Krieger EM, Júnior RF, Negrão CE, Lorenzi-Filho G. Day-night pattern of autonomic nervous system modulation in patients with heart failure with and without sleep apnoea. Int J Cardiol. 2011; 148(1):53-8.

45. Seals DR, Suwarno NO, Dempsey JA. Influence of lung volume on sympathetic nerve discharge in normal humans. Circ Res. 1990;67:130-41.

46. Naughton MT, Floras JS, Rahman MA, et al. Respiratory correlates of muscle sympathetic nerve activity in heart failure. Clin Sci (Lond). 1998;95:277-85.

47. van de Borne P, Oren R, Abouassaly C, et al. Effect of Cheyne-Stokes respiration on muscle sympathetic nerve activity in severe congestive heart failure secondary to ischemic or idiopathic dilated cardiomyopathy. Am J Cardiol. 1998;81:432-6.

48. Solin P, Kaye DM, Little PJ, et al. Impact of sleep ap- 
noea on sympathetic nervous system activity in heart failure. Chest. 2003;123:1119-26.

49. Mansfield D, Kaye DM, Brunner La Rocca H, et al.
Raised sympathetic nerve activity in heart failure and central sleep apnoea is due to heart failure severity. Circulation. 2003;107:1396-400. 